\title{
Sideband noise mitigation in a co-located network involving CDMA2000 and WCDMA system
}

\section{Nosiri Onyebuchi Chikezie ${ }^{1}$, Onoh Gregory Nwachukwu², Chukwudebe Gloria Azogini', Azubogu Austin Chukwuemeka ${ }^{3}$}

${ }^{1}$ Department of Electrical \& Electronic Engineering, Federal University of Technology Owerri, Nigeria

${ }^{2}$ Department of Electrical \& Electronic Engineering, Enugu State University of Science \& Technology, Nigeria

${ }^{3}$ Department of Electronic and Computer Engineering, Nnamdi Azikiwe University Awka, Nigeria

\section{Email address:}

buchinosiri@gmail.com (Nosiri O. C.),gnonoh@gmail.com (Onoh G. N.), gloriachukwudebe@yahoo.com (Chukwudebe G. A.), autinazu@yahoo.com(Azubogu A. C.)

\section{To cite this article:}

Nosiri Onyebuchi Chikezie, Onoh Gregory Nwachukwu, Chukwudebe Gloria Azogini, Azubogu Austin Chukwuemeka. Sideband Noise Mitigation in a Co-Located Network Involving CDMA2000 and WCDMA System. American Journal of Networks and Communications. Vol. 3, No. 2, 2014, pp. 17-24. doi: 10.11648/j.ajnc.20140302.11

\begin{abstract}
The installation of base station antennas within close frequency range in a co-located scenario constitutes a major interference for radio spectrum engineers. In a co-located setting involving a downlink frequency of CDMA2000 (1960 $-1990 \mathrm{MHz})$ and an uplink frequency of WCDMA $(1920-1980 \mathrm{MHz})$ as used in the telecommunication industry in Nigeria, the base station receiver is required to receive low amplitude desired signals in the presence of strong transmitting power signals resulting to sideband noise interference. The paper identifies the major mechanism of the sideband noise and proposes the application of a Butterworth Band Pass Filter (BBPF) as a mitigation technique. The technique was developed through the applications of empirical and mathematical analysis conducted in two different scenarios to evaluate the levels of the interference signals on the WCDMA receiver from CDMA2000 transmitter. The first scenario involved a standalone un-collocated WCDMA network while the second scenario involved a co-located network (CDMA2000 and WCDMA). A $52 \mathrm{~dB}$ required attenuation specification was obtained for the BBPF design.
\end{abstract}

Keywords: Sideband Noise, WCDMA, CDMA2000, Co-Location, BBPF

\section{Introduction}

Wireless communication technologies having evolved over the years are faced with diverse challenges which the wireless service providers must find ways to navigate for quality service delivery. The desire for wireless service providers to build more cell sites is accelerated by the following factors [1]:

- The need to provide coverage to a geographic region where the service provider has not previously served.

- To cover "dead spot" or areas where existing signals are weak.

- To allow for the reuse of channels or spectrum bandwidth to support a larger number of customers and to meet the higher speed requirements of emerging technologies.

The demand to meet these needs has led to the proliferation of new cell towers which are capital intensive. Possible solution to the proliferation of cell towers is the placement of a number of Radio Frequency (RF) transceiver antennas at close proximity to one another, a concept known as co-location [2].

The benefits of co-location strategy are summarized as follows $[3,4]$ :

- To reduce the proliferation of towers by facilitating sharing thereby maximizing the use of network facilities.

- To co-locate more networks on the same tower to optimize saving and efficient utilization of capital and operational expenditure for site infrastructure and to achieve improved network coverage and capacity.

- To promote fair competition through equal access being granted to the installations and facilities of operators on mutually agreed terms.

- To ensure that the economic advantages derivable from the sharing of facilities are harnessed for the overall benefits of all telecommunication stakeholders.

- To protect the environment from harmful interference. 
- To encourage operators to pursue a cost-oriented policy with the added effect of a reduction in the tariffs chargeable to consumers.

Co-location strategy was introduced in Nigeria by the Nigerian Communications Commission (NCC), primarily aimed at reducing capital and operating expenditure of cell sites and also to extend telecommunication services to the un-served and under-served communities in Nigeria [5].

Operators such as MTN, Etisalat, Globalcom, Visaphone, Airtel and Starcomms seeking to expand their network services by building new cell sites are regulated and managed by the NCC licensed service vendors such as the IHS Plc, Swap Technologies, MTI and Helios Towers [6].

One of the essential considerations when analyzing a co-located network is to evaluate if the frequencies of the networks are adjacent to each other, overlap or have close ranges.

However, networks involving the WCDMA (e.g MTN operator) and the CDMA (e.g VISAPHONE operator) at $1.9 \mathrm{GHz}$, when co-located are bound to experience interference due to the close frequency bands of operations between the networks.

The illustrations in Fig. 1 show the frequency spectrum allocation by International Telecommunication Union (ITU) for WCDMA, CDMA2000 and the Universal Mobile Telecommunication System (UMTS) respectively [7]. The frequency band allocation for CDMA 2000 downlink is between $1930-1990 \mathrm{MHz}$ and that of WCDMA uplink is between 1920-1980MHz. From Fig 1, it shows that the CDMA2000 transmitter (Tx) frequency band overlaps with the WCDMA receiver band by $50 \mathrm{MHz}$. Therefore, the two frequency bands will interfere in a co-located setting.

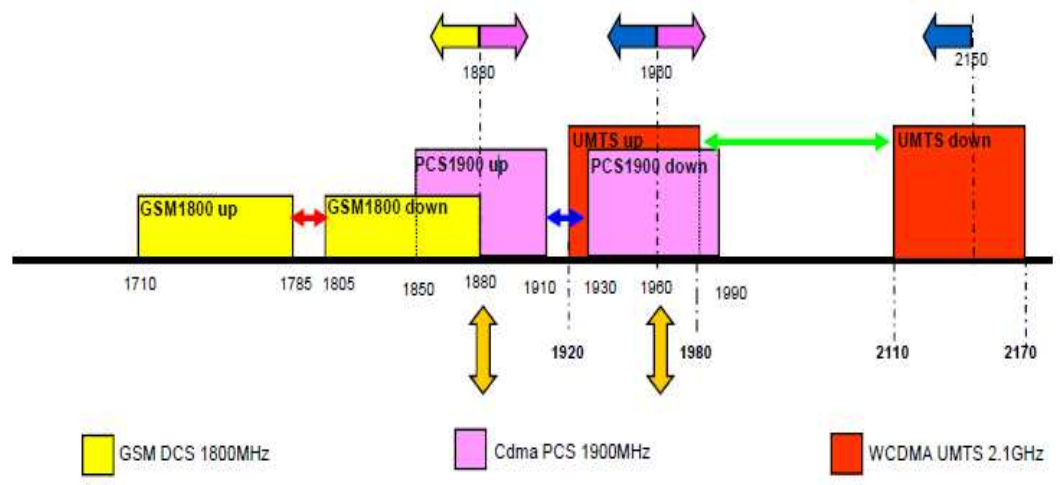

Figure 1. Spectrum Frequency Band Allocation [7]

Considering the huge impact of the interference between the two networks if co-located, the regulatory body (NCC) re-banded the frequency between these two networks as shown in Fig. 2. The new CDMA2000 downlink frequency band is between $1960-1990 \mathrm{MHz}$. Fig. 2 shows that the
CDMA2000 Tx band overlaps $20 \mathrm{MHz}$ on the WCDMA receiver $(\mathrm{Rx})$ band. There is no interference between UMTS base station (Bs) Tx and CDMA2000 Bs Rx because of wide frequency isolation band (see Table 1).

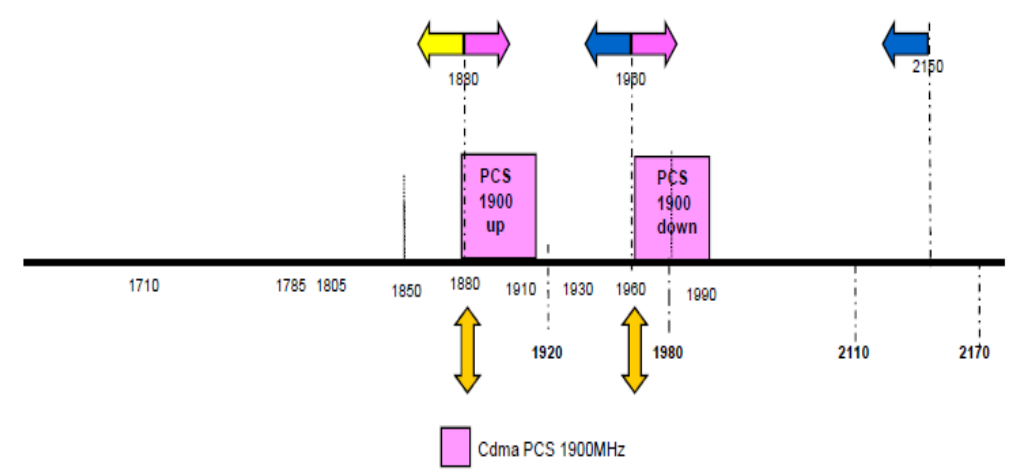

Figure 2. Spectrum Allocation by NCC (After re-banding) [8]

Table 1. Frequency spectrum allocation

\begin{tabular}{cccc}
\hline $\begin{array}{c}\text { Wireless } \\
\text { access } \\
\text { technology }\end{array}$ & $\begin{array}{c}\text { Mobile station } \\
\text { transmitter } \\
\text { (Uplink) (MHz) }\end{array}$ & $\begin{array}{c}\text { Base station } \\
\text { Transmitter } \\
\text { (downlink)(MHz) }\end{array}$ & $\begin{array}{c}\text { Duplex } \\
\text { separation } \\
\text { (MHz) }\end{array}$ \\
\hline CDMA 2000 & $1850-1910$ & $1930-1990$ & 80 \\
WCDMA & $1920-1980$ & $2110-2170$ & 190 \\
\hline
\end{tabular}

Fig. 3, shows the likelihood of spurious emissions levels on the receiving front end of the WCDMA from the CDMA2000(C2k) in a co-located scenario. 


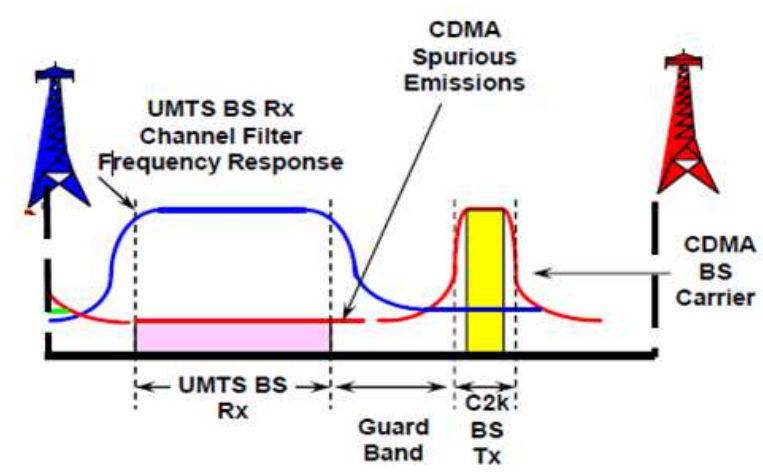

Figure 3. Spurious Emission level [8]

This work was therefore considered necessary because of the salient interference challenges faced between the CDMA2000 Tx band and the WCDMA Rx band at $1.9 \mathrm{GHz}$ in a co-located scenario, despite the re-banding by NCC. The co-location strategy investigated in this paper is mainly on passive sharing which involves non-electronic components and facilities such as towers, shelters, electric supply, easements and duct [9].

\section{The Mechanism of Sideband Noise}

In a co-located network, base station receivers have to receive weak desired signals in the presence of high power transmit signals which may lead to interference[10 ].

When RF signal is amplified to form the transmit signal, a significant amount of emissions are generated outside the transmit band referred to as sideband noise emission [11]. The emissions are due to the non-linearity and noise generated inside the power amplifier, and may appear as a "skirt" or "shoulders" when observed through the power spectrum at the output of power amplifier. These emissions or undesired noise energy may fall within the pass bands of a co-located receiver, degrading the receiver sensitivity with corresponding rise in the total noise floor level [11]. These undesired noise energy also contribute to the Carrier to Interference $(\mathrm{C} / \mathrm{I})$ ratio degradation, reduction in the full utilization of the capacity and the coverage radius, thereby disfranchising the end users from enjoying their hard paid services. Therefore, the undesired spectral components have to be reduced to an acceptable performance level to avoid the introduction of excessive noise in the receiver.

\section{Methodology}

The first step in recognizing if interference has corrupted a receiver system is to understand the characteristics of the signal that the affected system is intended to receive while the second step requires determining the level of the interfering power that affects the amplitude of the received signal.

In this research, the interference leakage of the CDMA2000 Tx signal power on WCDMA Rx signals was investigated. The test network was set up in Enugu State, involving a co-located site and an unco-located site respectively. The co-located site, involving CDMA2000 and WCDMA systems with separate antennas placed vertically collinear to each other, situated at the Federal Housing Estate Trans Ekulu Enugu, Enugu. This site has the following characteristics: Visa ID: ENU005, HIS ID:IHS_ENG_007, Network operators: MTN and Visaphone, BTS Local cell ID: 2155, sector ID: 0, Carrier ID: 18.

The unco-located site involves a standalone WCDMA, situated at Independent Layout New Haven, Enugu, characterized by the following: Site ID: HENB549, Cell ID: EN0099C, longitude and latitude of 7.5286945 and 6.44658 respectively, the network operator is MTN. All the sites were situated in urban environment.

A detailed experiment was carried out to measure the interference leakage using a Huawei software M2000 Service Maintenance System CBSS installed in a laptop. The software provided a window where the sites to be investigated were selected within the sector, carrier and duration. The measurement was carried out remotely from the IHS central office.

\subsection{Empirical Analysis and Evaluation for the Un-Collocated Network}

The received signal power for the WCDMA was measured, conducted from Huawei site. The Noise Figure (NF) of the WCDMA signals was calculated and obtained as $5 \mathrm{~dB}$ using "(1)".

$$
N F(d B)=M D S(d B m)-K T_{0} B_{c}[12]
$$

Where:

- $\mathrm{MDS}$ is the minimum detectable signal $(-102 \mathrm{dBm})$ for WCDMA network [12]

- $\quad k$ is the Boltzmann's constant $\left(1.38 \times 10^{-23} \mathrm{~J} / k,\right)$

- $T_{0}$ is the ambient temperature in Kelvin $\left(T_{0}=290 \mathrm{k}\right)$

- $B_{c}$ is the channel bandwidth for the WCDMA (5MHz)

The following parameters were obtained by calculation: the noise floor level and the minimum demodulation $\mathrm{C} / \mathrm{I}$ ratio.

\section{- The Noise Floor Level}

Calculating the receiver's noise floor level requires the knowledge of the noise figure (NF). The model in "(2)" was used to calculate the noise floor level.

$$
N_{\text {floor }}=10 \frac{K T_{0} B_{s}+N F}{10}(\mathrm{~mW})[13]
$$

Where $B_{s}$ is the signal bandwidth of WCDMA $(3.84 \mathrm{MHz})$.

\section{- The Minimum Demodulation Carrier to Interference (C/I) Ratio}

The $\mathrm{C} / \mathrm{I}$ ratio in a communication channel characterizes the quality with which information is transferred through the 
channel. Equation (3) is used to calculate the minimum demodulation of the $\mathrm{C} / \mathrm{I}$ ratio.

$$
\left(\frac{C}{I}\right)_{m}=S_{0}-N_{\text {floor }}[13]
$$

Where $S_{0}$ is receiver sensitivity.

The summary of the results obtained are shown in Table 2 .

\subsection{Empirical Analysis and Evaluation for the co-Located Network}

In this scenario, the measurements and evaluation of the interfering signal power, noise floor level, minimum Demodulation Carrier to Interference ratio and percentage $\mathrm{C} / \mathrm{I}$ ratio degradation respectively for the co-located networks were considered. The parameters measured include:

i. The CDMA2000 Tx signal power.

ii. The WCDMA Rx signal power.

The BTS transmitter power and the BTS received signal power were measured using Huawei software M2000 Service Maintenance System (CBSS). The summary of the measured and calculated results are shown in Table 3.

The following parameters were calculated:

\section{- The Noise Floor Level}

The difference in the received signal level for co-located and unco-located networks gives the degraded receiver sensitivity denoted as $\eta$. If the receiver sensitivity is degraded by $\eta \mathrm{dB}$ then the interference plus noise power is given by

$$
N_{\text {floor }}+\text { Interference }=10 \frac{K T_{0} B_{s}+N F}{10} 10 \frac{\eta}{10}(\mathrm{~mW})[13]
$$

If the interference level is equal to the equivalent noise level of the original signal, the signal sensitivity will be degraded by $3 \mathrm{~dB}$ [7]. Therefore, it is important to ensure that the noise level of the original signal is always $3 \mathrm{~dB}$ above the interference noise level to maintain victim's percentage ratio [7].

\section{- $\quad$ The Interfering Signals Power}

In the process of proffering solution to this prevailing interference, one of the vital considerations is to evaluate the degree and the impact of the interfering power on the victim receiver channel especially on the system receiver sensitivity and noise floor level. Therefore the interfering power at the receiver input, denoted as $(\gamma)$ is calculated using "(5)".

$$
\gamma=\left(K T_{0} B_{s}+N F\right)+10 \log _{10}\left\{10 \frac{\eta}{10}-1\right\} d B m[13]
$$

This is expressed in terms of erosion of the receiver sensitivity. By definition, a degradation of receiver sensitivity $(\mathrm{dB})$ is equal to the increase in the total noise plus interference [7]. This denotes that if the noise level at the receiver increases by $1 \mathrm{~dB}$, the receiver sensitivity of the
BTS decreases by $1 \mathrm{~dB}$ accordingly.

\section{- $\quad$ The Minimum Demodulation Carrier to Interference} (C/I) Ratio

The minimum demodulation carrier to interference ratio $(\mathrm{dB})$ in a co-located network is obtained using "(6)" and the result shown in Table 3 .

$$
\left(\frac{C}{I}\right)_{m}=S_{0}-\left(N_{\text {floor }}+\text { Interference }\right)[13]
$$

\section{Results and Discussion}

Tables 2 and 3 show the detailed summary of the data obtained for the co-located and un-collocated networks.

Table 2. Summary of data obtained for the un-collocated WCDMA site.

\begin{tabular}{lll}
\hline $\mathbf{S} / \mathbf{N}$ & Parameter & Obtained values \\
\hline 1 & $\begin{array}{l}\text { Measured Received signal strength for } \\
\text { the WCDMA network }\end{array}$ & $-109.69 \mathrm{dBm}$ \\
2 & $\begin{array}{l}\text { Calculated Noise floor for the WCDMA } \\
\text { network }\end{array}$ & $-103 \mathrm{~dB}$ \\
3 & $\begin{array}{l}\text { Calculated Minimum demodulation C/I } \\
(\mathrm{dB}) \text { for the WCDMA network }\end{array}$ & -6.69 \\
\hline
\end{tabular}

Table 3. Summary of the data obtained for the co-located network.

\begin{tabular}{clc}
\hline S/N & Parameter & Obtained values \\
\hline 1 & $\begin{array}{l}\text { Measured Received signal strength for } \\
\text { the WCDMA network }\end{array}$ & $-110.70 \mathrm{dBm}$ \\
2 & $\begin{array}{l}\text { Measured Transmitter power for the } \\
\text { CDMA2000 }\end{array}$ & $41 \mathrm{dBm}$ \\
3 & $\begin{array}{l}\text { Calculated Noise floor for the WCDMA } \\
\text { network }\end{array}$ & $-101.99 \mathrm{~dB}$ \\
4 & $\begin{array}{l}\text { Calculated interfering signal power } \gamma) \\
\text { for the WCDMA network }\end{array}$ & $-108.80 \mathrm{dBm}$ \\
5 & $\begin{array}{l}\text { Calculated Minimum demodulation C/I } \\
\text { ratio (dB) for the WCDMA network }\end{array}$ & -8.71 \\
6 & $\begin{array}{l}\text { Calculated C/I ratio degradation for } \\
\text { the WCDMA network }\end{array}$ & 2.01 \\
7 & $\begin{array}{l}\text { Calculated percentage C/I ratio } \\
\text { degradation for the WCDMA network }\end{array}$ & 30 \\
8 & $\begin{array}{l}\text { Calculated Receiver sensitivity } \\
\text { degradation }(\eta) \\
\text { for the WCDMA network }\end{array}$ & $1.01 \mathrm{dBm}$ \\
\hline
\end{tabular}

The behaviour and performance analysis of any system is better explained using graphical representations. The simulated performance results obtained using Matlab 7.0 software tool was shown in Figs. 4-8. The graphs show the various performance effects of interfering power on the system reciever sensitivity and noise floor level. The minimum demodulation $\mathrm{C} / \mathrm{I}$ ratio after the system is interfered and the percentage $\mathrm{C} / \mathrm{I}$ ratio degradation effects were also graphically represented. 


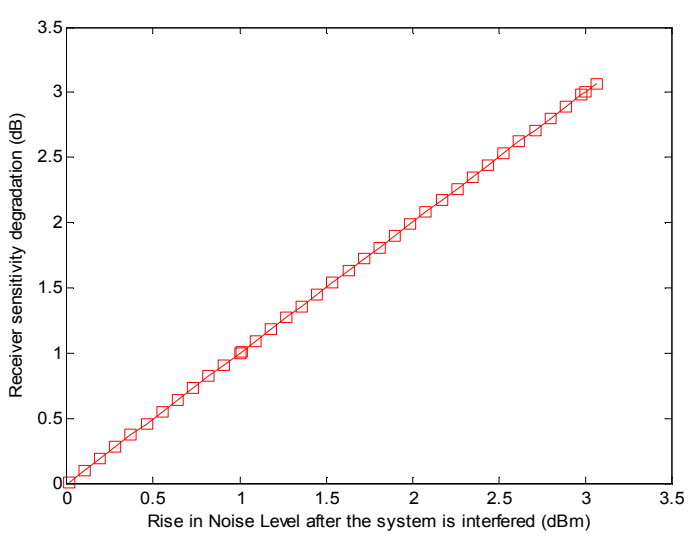

Fig. 4. Interference effect on the system noise level performance

The linear graph in Fig. 4 shows the performance effect of receiver sensitivity degradation caused by the interfering power on the rise noise floor level. A receiver sensitivity degradation of $1.01 \mathrm{dBm}$ gave rise to increase in noise floor level by same value.

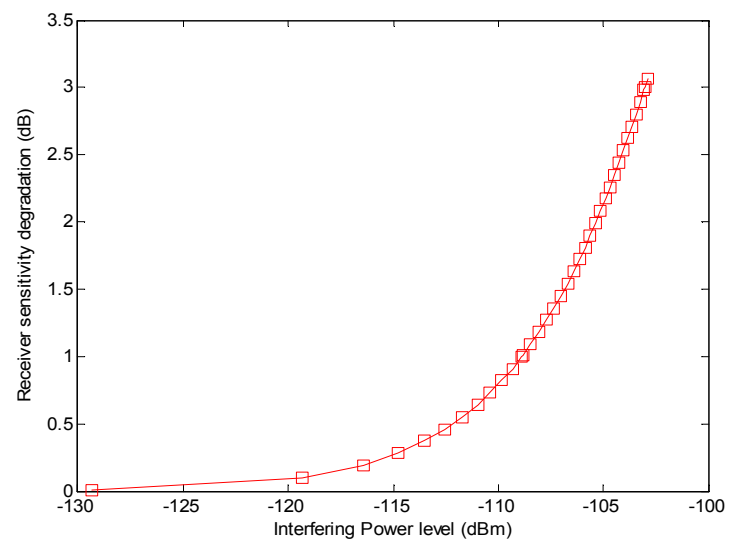

Fig. 5. Effect of rise in interfering power on the system sensitivity.

The exponential performance of the graph of Fig. 5 shows the effects of the CDMA2000 interfering power on the WCDMA receiver sensitivity. Interfering power level of $-108.80 \mathrm{dBm}$ degrades the sensitivity of the receiver by $1.01 \mathrm{dBm}$. Hence as the interfering power increases, the receiver sensitivity (victim receiver) degrades exponentially.

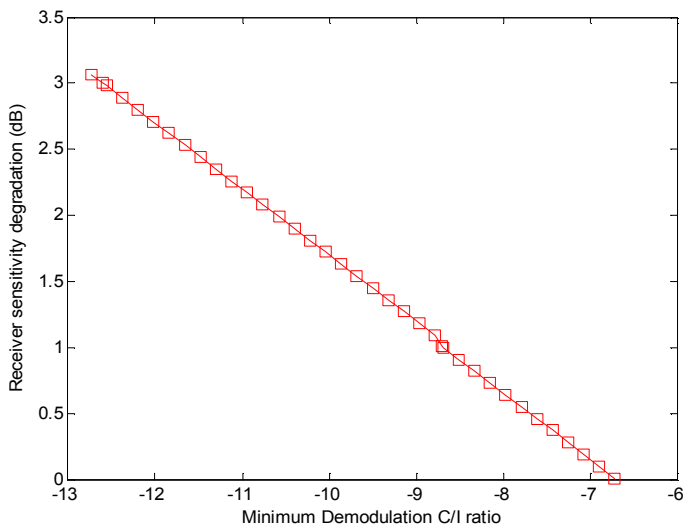

Fig. 6. Minimum demodulation C/I ratio after the system is interfered.
The negative slope in Fig. 6 shows the relationship between the receiver sensitivity degradation of the victim receiver and the minimum demodulation Carrier to Interference ratio. When the receiver sensitivity degrades by 1.01 , the minimum demodulation $\mathrm{C} / \mathrm{I}$ ratio decreases by -8.71 .

Fig.7 shows the performance characteristics on the increase in interfering power level and its corresponding effects on the system noise floor. From the graph, increase in interfering power of $-108.80 \mathrm{dBm}$ gave rise to noise floor level of $1.01 \mathrm{dBm}$. This graph further explains the negative impact of the sideband noise on the channel capacity of the victim receiver. As the noise floor level increases, the overall system capacity reduces, giving rise to poor channel capacity performance. This means that only fewer subscribers may be accommodated.

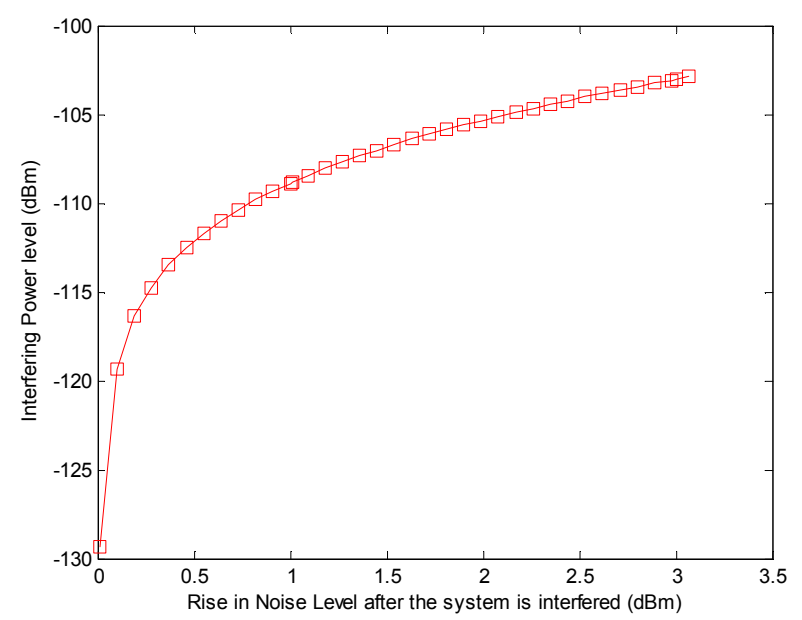

Fig. 7. Rise in system noise floor level after the system is interfered.

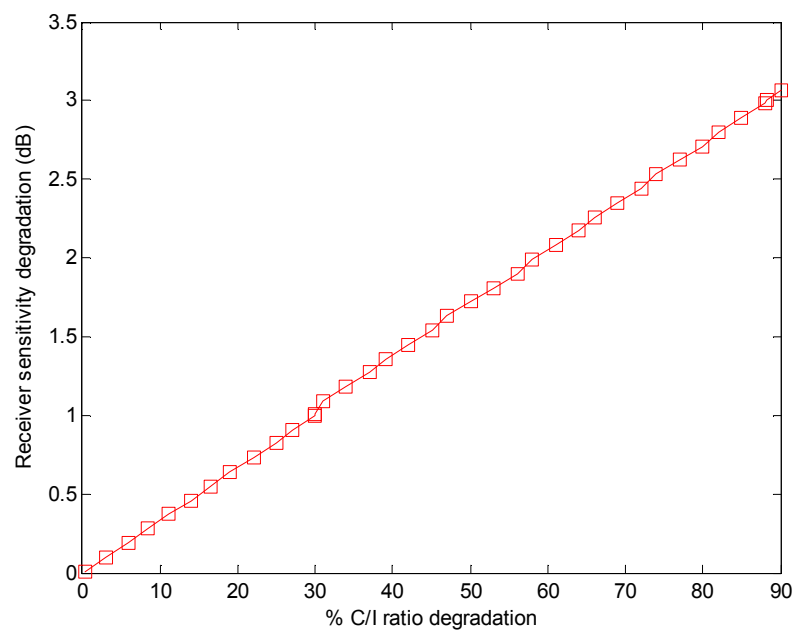

Fig. 8. Percentage C/I ratio degradation after the system is interfered

Fig. 8 clearly explains the percentage degradation performance of the carrier to interference ratio as the receiver sensitivity further degrades. From the graphical representation, $1.01 \mathrm{dBm}$ sensitivity degradation resulted to $30 \% \mathrm{C} / \mathrm{I}$ ratio reduction. The degradation of the $\mathrm{C} / \mathrm{I}$ ratio 
impacts negatively on the system channel capacity. If not controlled with adequate measures, it could reduce the assigned number of subscribers within the channel.

The summary results from the graph show the following important points:

1. Increase in Interference power of CDMA2000 increases the WCDMA noise level and reduces the sensitivity of the receiver antenna, leading to high call drop rate, hence restraining subscribers from enjoying consistent and high quality services in a WCDMA cell.

2. Interference decreases WCDMA capacity due to the rise in the noise level, hence fewer subscribers will only be accommodated.

3. $1.01 \mathrm{~dB}$ degradation gave rise to $1.01 \mathrm{~dB}$ noise floor and interfering power of $108.80 \mathrm{dBm}$

\section{- Butterworth Band Pass Filter (BBPF) Design Procedure}

The limits of spurious emission levels by the Three Generation Partnership Project Two (3GPP2) for CDMA far offset from carrier is given as: $-13 \mathrm{dBm} / 1 \mathrm{MHz}$ $(1 \mathrm{GHz}<\mathrm{f}<5 \mathrm{GHz})[8]$.

In order to guarantee that the affected receiver's performance will not degrade, the isolation between the interfering transmitter and affected receiver should be:

$$
-13 \mathrm{dBm} / 1 \mathrm{MHz}-(-108.80 / 3.84 \mathrm{MHz})=101.80 \approx 102 \mathrm{~dB}
$$

The total isolation required to maintain the received signal optimum performance in the co-located scenario is $102 \mathrm{~dB}$. The standard antenna-to-antenna isolation specification $(\mathrm{dB})$ by the NCC for personal communication systems (PCS), digital communication systems (DCS) and universal mobile telecommunication systems (UMTS) in a co-located site is $50 \mathrm{~dB}[6]$. Therefore a $52 \mathrm{~dB}$ rejection at $5 \mathrm{MHz}$ guard band was obtained as the required specifications for the Butterworth Band Pass Filter (BBPF) offset from the low side edge of the pass band. A guard band of $5 \mathrm{MHz}$ pass band was considered in other to offer a faster roll-off space for the BBPF.

\section{- $\quad$ BBPF Design Specifications}

The BBPF was primarily considered in this work among other infinite impulse response filters (IIR) because of its attributes to the least amount of phase distortion. Every filter design requires creating the filter coefficients to meet specific filtering requirements. The specifications in Hertz are converted to normalized frequencies $(\omega)$ using "(8)":

$$
\omega=\frac{2 \pi f}{f_{s}}
$$

Where:

$f$ is the absolute frequency in Hertz, $f_{s}$ is the sampling frequency in samples/second and $\omega$ is the normalized frequency in $\pi$ radian/sample. Tables 4 and 5 , show the Frequency and Magnitude specifications for the BBPF.
Table 4. Frequency Specifications

\begin{tabular}{ccc}
\hline $\begin{array}{c}\text { Filter } \\
\text { parameters }\end{array}$ & $\begin{array}{c}\text { Frequency } \\
\text { specifications(KHz) }\end{array}$ & $\begin{array}{c}\text { Normalized } \\
\text { frequency }(\omega) \\
(\pi \text { radian/samples })\end{array}$ \\
\hline $\mathrm{F}_{\text {stop1 }}$ & 1955000 & $0.4912=\boldsymbol{\omega}_{\text {Stop } 1}$ \\
$\mathrm{~F}_{\text {pass1 }}$ & 1960000 & $0.4924=\boldsymbol{\omega}_{\text {Pass } 1}$ \\
$\mathrm{~F}_{\text {pass2 }}$ & 1990000 & $0.5000=\boldsymbol{\omega}_{\text {Pass } 2}$ \\
$\mathrm{~F}_{\text {stop2 }}$ & 1995000 & $0.5012=\boldsymbol{\omega}_{\text {Stop } 2}$ \\
& Sampling frequency & \\
\hline
\end{tabular}

Table 5. Magnitude Specifications.

\begin{tabular}{cc}
\hline Filter parameters & Magnitude specifications \\
\hline $\mathrm{A}_{\text {stop1 }}$ & $52 \mathrm{~dB}$ \\
$\mathrm{~A}_{\text {pass }}$ & $0.1 \mathrm{~dB}$ \\
$\mathrm{~A}_{\text {stop } 2}$ & $52 \mathrm{~dB}$ \\
\hline
\end{tabular}

Where;

$\mathrm{F}_{\text {pass } 1}$ : Frequency at the edge of the start of the pass band. $\mathrm{F}_{\text {pass } 2}$ : Frequency at the edge of the end of the pass band. $\mathrm{F}_{\text {stop } 1}$ : Frequency at the edge of the start of the first stop band,

$\mathrm{F}_{\text {stop2 }}$ : Frequency at the edge of the start of the second Stop band,

$\mathrm{A}_{\text {stop } 1}$ : Attenuation in the first stop band in $\mathrm{dB}$

$A_{\text {Pass }}$ : Amount of ripple allowed in the pass band, known as the single pass band gain parameter

$\mathrm{A}_{\text {stop2: }}$ : Attenuation in the second stop band in $\mathrm{dB}$

The output result interprets that any interfering signal that comes out of the filter must be $52 \mathrm{~dB}$ lower than it went in. In practice, the designed filter should be placed at the CDMA2000 front end to reject the sideband noise falling within the WCDMA receiver pass band. The graphs in Figs. 9 and 10 show the magnitude response and the phase response of the designed filter.

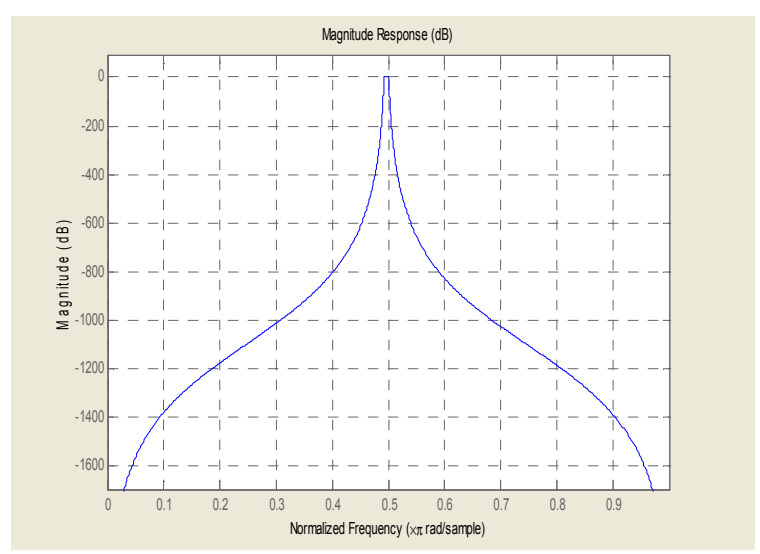

Fig. 9. Magnitude response of Butterworth Bandpass filter. 


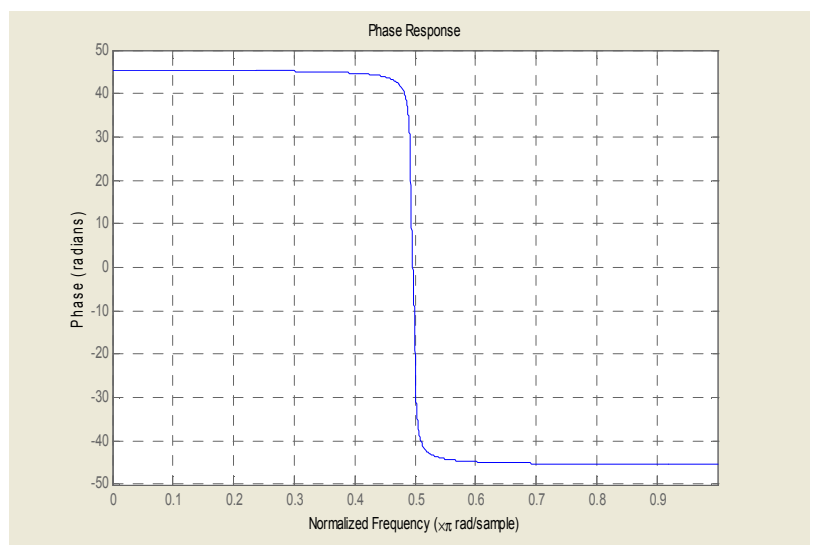

Fig. 10. Phase response of Bandpass filter monotonically and generates a maximally flat response with no ripples both in the pass band and stop band, this provided a sharp phase linear response with minimal or no distortion.

The graph in Fig. 9 shows a symmetrical magnitude response of the BBPF. Great importance was given to the magnitude response to show how selectively the filter performs as it gets steeper and also the cut-off frequencies. The first cut-off frequency (3-dB point) and the second cut-off frequency were obtained as $0.49215 \pi \mathrm{rad} / \mathrm{sample}$ and $0.50025 \pi \mathrm{rad} / \mathrm{sample}$ respectively.The geometric mean of the upper and lower 3-dB cut-off frequencies was evaluated as $0.4962 \pi \mathrm{rad} / \mathrm{sample}$. The geometric mean value identifies the point at which the filter achieves its maximum gain.

Phase response is the phase shift of the output relative to its input. Fig.10 shows how the filter response decreases

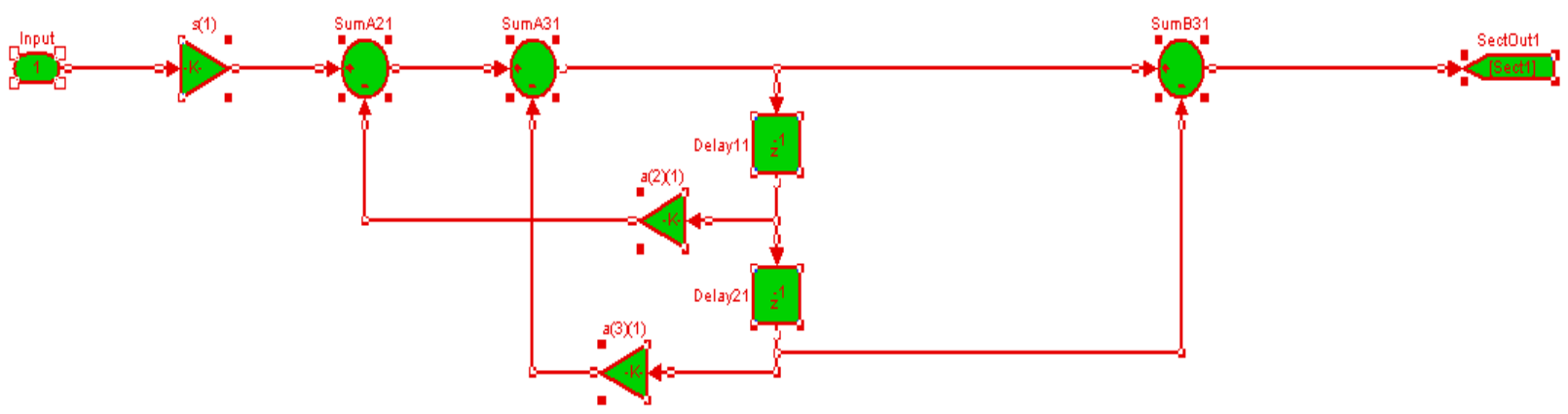

Fig. 11. Simulink block for the Band pass filter

Fig. 11 shows the Simulink block function parameters of the designed BBPF. It shows the first section out of the cascaded 29 sections. The function block parameters represented the gains and the delay samples. Implementation of this filter as a cascade of quadratic factors provides a better control of the stability of the filter.

\section{Conclusion}

The detailed performance effects of the interfering noise power on the receiver sensitivity, noise floor level and the carrier to interference ratio were clearly evaluated. From the measurements conducted, the interfering power was evaluated as $-108.80 \mathrm{dBm}$, which gave rise to $1.01 \mathrm{dBm}$ receiver sensitivity degradation and $1.01 \mathrm{dBm}$ rise in total system noise floor, about $30 \%$ degradation in $\mathrm{C} / \mathrm{I}$ ratio. A $52 \mathrm{~dB}$ rejection at $5 \mathrm{MHz}$ guard band offset from the low side edge of the pass band was obtained. An application of BBPF was considered necessary as a tool designed to mitigate the challenging effects of sideband noise. In practice, the designed BBPF should be installed at the CDMA2000 front end to reject the sideband noise falling within the WCDMA receiver pass band.

\section{Recommendation for Further Work}

With the rapid increase in diversity in wireless communication systems especially when operating in a dynamic environment, the authors recommend the application of adaptive noise cancellation technique (ANCT) considering the limitations of the BBPF which includes:
a. Poor efficient power handling capability and

b. Low frequency agility response.

\section{References}

[1] P. Stox "Wireless co-location on towers and alternate structure" satellite broadcast TV, linksystem.uk.com. April, 2010 .

[2] Guidelines for siting and sharing of Telecommunication base station infrastructure, "Rwanda Utilities Regulatory Agency" RURA/ICT infraDev/Dev/G02/2011. Pp 10-12, 2011.

[3] Guidelines on Collocation and Infrastructure Sharing Issued by the Nigerian Communications Commission, pp 1-2, 2010

[4] S. Opara, I. Iteun, "Option for Telecoms operators during recession". A published article pp1-2, June, 2009

[5] F.E. Idachaba, "Telecommunication Cost Reduction in Nigeria through Infrastructure Sharing between Operators". Pacific Journal of Science and Technology. 11(1):272-276, 2010.

[6] Nigeria Communications Week "Managed services in Nigeria “, March 11, 2012. 
[7] Chen Xinting, "Analysis of co-site interference between different mobile communication system", wireless technical support department, Huawei technologies Co. Ltd, pg 9, 2008.

[8] Trino G., Chen L., "interference analysis between co-located networks in Nigeria", $R F$ design Manager from Starcomms $2^{\text {nd }}$ version, 2007.

[9] Policy on co-location and infrastructure sharing in SAMOA. Office of the regulator, pp 4-8, March, 2012

[10] S. Ahmed, "Interference mitigation in co-located wireless systems". A PhD thesis, School of Engineering and Science, Faculty of Health, Engineering and science, Victoria University, pg 3, Dec., 2012.
[11] A. Roussel "Feedforward interference cancellation system applied to the $800 \mathrm{MHz}$ CDMA cellular band". A Master of applied science in Electrical Engineering. Ottawa-Carleton Institute. Pg 6, 2003.

[12] Chenung, Tze Chiu, "Radio Performance", Chapter 4 Virginia Tech: ETD 122298 pp 96-99, 2009

[13] Montegrotto T. "Practical Mechanism to Improve the Compatibility between GSM-R and Public Mobile Networks and Guidance on Practical Co-ordination", ECC Report 162, p. 40 May, 2011. 